\title{
DITOS E NÃO DITOS SOBRE O PERFIL DO PROFESSOR ANGOLANO EM TEXTOS JORNALÍSTICOS \\ SAID AND UNSAID ABOUT THE PROFILE OF THE ANGOLAN TEACHER IN JOURNALIST TEXTS
}

\author{
Adriana Santos Batista* \\ Milan Puh ${ }^{* *}$
}

\begin{abstract}
RESUMO: Neste artigo, é apresentada uma análise de discurso jornalístico acerca das representações sobre o perfil de professor na educação angolana. O objetivo é discutir, linguística e discursivamente, como os meios de comunicação abordam aspectos ligados à educação, com foco na análise dos ditos e não ditos em concurso público para professor de rede pública em Angola, no ano de 2018. Para tanto, foram utilizadas as contribuições teórico-metodológicas de Pêcheux (1988) sobre o interdiscurso e Orlandi (1997) a respeito do silêncio, importantes para o entendimento do "jogo discursivo" entre o dito e não dito sobre o perfil do professor. Para a composição do corpus, foram considerados 14 textos publicados em 2018 no Jornal de Angola. Tal recorte temporal foi estabelecido por coincidir com a realização do concurso público que foi amplamente abordado pela mídia, constituindo a nossa hipótese de que os aspectos abordados pelos meios de comunicação são aqueles para os quais se busca adesão por parte dos governantes. Dessa forma, haveria material para discutir como e quais anseios do setor educacional sobre o futuro professor são representados pela mídia. Cabe ressaltar que as análises da interconexão entre diferentes tipos de discursos poderão possibilitar uma maior compreensão de seu impacto no imaginário que se constrói acerca dos professores, do ensino em geral e da solução para as dificuldades educacionais em Angola.
\end{abstract}

Palavras-chave: Concurso público; Discurso; Educação; Formações imaginárias.

ABSTRACT: In this article, we present an analysis of journalistic discourse about the representations of the teacher profile in Angolan education. The objective is to discuss, linguistically and discursively, how the media approach aspects related to education, focusing on the analysis of what has been said and not said in a public tender for new teachers in the public sector in Angola, in the year 2018. In this manner, were used the theoretical-methodological contributions of Pêcheux (1988) on interdiscourse and Orlandi (1997) on silence, important for the understanding of the "discursive game" between the said and not said about the profile of the teacher. In order to compose the

\footnotetext{
* Doutorado em Filologia e Língua Portuguesa pela Universidade de São Paulo (USP). Docente da Universidade Federal da Bahia (UFBA). Contato: drisb11@yahoo.com.br

* Pós-doutorado pela Universidade Estadual do Centro-Oeste (Unicentro) e doutorado em Educação pela Universidade de São Paulo (USP). Professor substituto da USP. Contato: milan.puh1@gmail.com
} 
corpus, we considered 14 texts published in 2018 by the Jornal de Angola. Such a temporal definition was established because of its coinciding with the public tender that was widely covered by the media, so our hypothesis is that the aspects addressed by the media are those for which acceptance is sought by the government. In this way, there would be material to discuss how and which educational sector expectations of the future teacher are represented by the media. It should be emphasized that the analysis of the interconnection between different types of discourses may allow a better understanding of its impact on the imaginary that is built on teachers, teaching in general and the solution to the educational difficulties in Angola.

Keywords: Civil service examination; Discourse; Education; Imaginary formations.

\section{INTRODUÇÃO}

Em 2018, o debate em torno de temas educacionais em Angola foi marcado por muita discussão acerca de um concurso público nacional para professores da rede pública. O governo angolano, com vistas a reduzir o déficit no número de professores nos diferentes níveis de ensino, lançou um concurso público para preenchimento de vinte mil vagas para o magistério nas dezoito províncias do país. Oficialmente amparado no Despacho Conjunto 95/018, de abril de 2018, que divulgou suas regras e procedimentos, e no Despacho 232/018, emitido em maio do mesmo ano, que autorizou sua abertura, o concurso teve suas provas aplicadas em julho, com divulgação dos resultados em setembro, após a etapa de recursos. Segundo dados do Ministério da Educação, cento e trinta e cinco mil pessoas participaram do certame ${ }^{1}$, entretanto nem todas as vagas foram preenchidas, posto que foram aprovados somente 18.747 candidatos (Agência Angola Press, 2018).

Tanto por suas proporções quanto pelo impacto social previsto pela contratação de professores, o certame foi amplamente divulgado pelos meios de comunicação, desde a indicação dos requisitos para inscrição até as alterações nos critérios para classificação dos candidatos. Entre 06 de março e 19 de setembro de 2018, foram publicados pelo Jornal de Angola, publicação estatal, ao menos, quatorze textos que tiveram como foco a discussão sobre as

\footnotetext{
1 Nota de imprensa do Gabinete de Comunicação Institucional do Ministério da Cultura, publicado em 21 de julho de 2018.
} 
etapas da seleção. Considerando que se tratava de um processo com vistas à contratação de professores para ocupar postos em todo território nacional e que desde 2014 não havia concursos do tipo, os textos caracterizam-se como uma oportunidade para observar quais imagens e representações acerca dos professores se materializaram e circularam na mídia.

Para tal proposição, foram mobilizadas as concepções teóricas provenientes da Análise do Discurso, principalmente o conceito de formações imaginárias de Pêcheux (1988; 1997) e as discussões sobre silêncios e não ditos desenvolvidas por Orlandi (2005). Tais conceitos mostram-se produtivos para a análise dos textos jornalísticos em questão na medida em que permitem conjecturar não somente sobre as exigências para inscrição e aprovação, mas também observar como sua composição indicia e propaga características do perfil profissional pretendido, o que pode ultrapassar aspectos formativos e teóricos, além de permitir uma reflexão mais ampla sobre a educação no país.

Além disso, retoma-se a discussão teórico-metodológica da pesquisa realizada por Batista e Puh (2016) sobre visões e imaginários acerca da educação no que diz respeito ao material propagandístico da Prefeitura do Rio de Janeiro, em que se tomaram como base multimodalidade e interdiscursividade para continuar a discussão sobre como os modos de identificar e discutir significados não previstos por seus produtores podem ocorrer quando de sua divulgação. Neste texto, no entanto, o propósito reside na análise entre os níveis do dito e não dito, elementos que mais se sobressaíram nas leituras iniciais e que permitem traçar esse perfil e vinculá-lo à imagem esperada do professor de ensino público no país. Por se tratar de uma análise de discurso jornalístico que aborda a realização do concurso para novos professores e todas as peripécias decorrentes de sua realização, é importante situar o leitor no contexto mais amplo da administração pública angolana. 


\section{CONTEXTO EDUCACIONAL}

Os aspectos no jornal podem ser mais bem entendidos ao se considerar que Angola passou por um período colonial que marcou intensivamente a sua administração pública, à qual pertence a Educação, pelo predomínio de administração central, movida pelo autoritarismo político e intervencionismo econômico português, segundo Valadares et al. (2013). De acordo com os autores, após a independência em 1974 foi instaurado um sistema político chamado de revolucionário com regime político único e uma organização administrativa centralizada, seguindo os princípios de "centralismo democrático" em que a maioria das decisões era tomada a nível central. E um terceiro momento se faz presente com a reforma administrativa de 1990, que seguiu as transformações do país, encaminhando-se para o que se chama de período democrático, no qual teria acontecido uma superficial desconcentração da administração pública, na visão de Antônio (2004). Assim, Valadares et al. citam que o aparelho público no país pode se enquadrar nos marcos políticos e históricos que afetaram o país desde a sua colonização.

Acrescenta-se que essa classificação define o sistema predominante naquele momento, mas que, de fato, na atualidade é possível observar características dos três períodos, o que também pode ser notado no caso da Educação, especificamente. Segundo Silva (2013), em 1978 começa a implantação de um novo sistema educativo em que houve uma "explosão" de número de alunos, uma característica considerada constante em Angola. Segundo ela, o sistema educativo não pôde se desenvolver de modo adequado durante as décadas de guerra civil, com "a destruição quase total de grande parte das infraestruturas escolares" (2013, p. 53). E complementa que um dos principais problemas da reconstrução nacional é "precisamente o défice de mão-de-obra qualificada, a falta de competitividade e a crescente taxa de desemprego".

Num período posterior, iniciado com a paz de 2002, a educação recebeu a Lei 13/01, promulgada em 31 de dezembro de 2001 e nomeada como Lei de Base do Sistema Educativo, que previa a universalização do ensino primário. 
Posteriormente, foi publicado o Plano de Implementação Progressiva do Novo

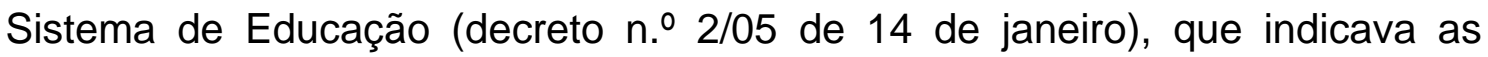
seguintes fases de implantação do novo sistema: 1) preparação, 2) experimentação, 3) avaliação e correção, 4) generalização e 5) avaliação global. No Balanço da Implementação da $2^{\underline{a}}$ Reforma Educativa em Angola, (ANGOLA, 2011), em trecho dedicado a discutir as perspectivas futuras quanto à reforma, são inseridas as seguintes projeções com relação à seleção de professores:

[Ensino primário - primeiro ciclo] Seleccionar, com rigorosidade, os professores candidatos a leccionar as disciplinas de Língua Portuguesa, Educação Laboral, Educação Visual e Plástica, Educação Moral e Cívica, Educação Física, Inglês e Francês. (p. 63)

[Formação média normal] Organizar Concurso Público para admissão de professores com formação pedagógica, no sentido de satisfazer as necessidades de acordo com o Plano de Estudo. (p. 65)

Para além da previsão de contratação de professores mediante concurso público, o relatório deixa claro que tais seleções deveriam ocorrer com "rigorosidade". Tal qualificação do ato de selecionar evidencia que, embora houvesse grande demanda por professores para reformulação do sistema educativo, a qualidade desses profissionais era traço que não poderia ser deixado em segundo plano em prol da quantidade de aprovados em eventuais concursos e seleções. Acrescenta-se que, apesar de nos últimos anos ter havido um aumento no número de crianças que ingressaram no sistema escolar, ainda há muitas fora da escola, o que intensifica a necessidade de professores a serem contratados. Segundo dados do site da Unicef (2018):

Em Angola, de 2001 até 2014, o número de crianças que ingressaram na escola quase quadruplicou. A qualidade e eficiência da oferta educativa tem merecido a atenção do Governo e dos seus principais parceiros.

Contudo, cerca de $22 \%$ das crianças em Angola ainda se encontram fora do sistema de ensino e $48 \%$ das crianças matriculadas não concluem o ensino primário. Apenas $11 \%$ das crianças dos 3 aos 5 anos têm acesso à educação pré-escolar. 
Assim, o país encontra-se em um momento de reflexão sobre as necessárias mudanças para o fortalecimento de seu sistema educacional e, ao mesmo tempo, tem de continuar com a reforma. Outros estudiosos, como Silva (2013), dão mais ênfase à formação contínua, procurando definir a educação docente em diferentes níveis de formação, ao identificar três gerações ao longo da história do país: primeira geração, que envolve professores "sem agregação pedagógica e com educação básica mínima” (p. 90); segunda geração, com professores que fizeram oito anos de estudos, a qual, teria sido massivamente recrutada em 2006 "para responder às urgências de cobertura" (idem) e uma futura terceira geração que abrangeria os professores que "possuem agregação pedagógica", isto é, fizeram cursos universitários superiores em que receberam uma formação específica na área da Educação.

Tal aspecto contraria em certo grau os posicionamentos do governo, que se propõe a criar e inserir em grande escala de professores, salas de aula e escolas, citando números estatísticos, sendo essa quantificação nos textos jornalísticos o que mais imediatamente chama a atenção. Articulam-se essas reflexões com o que já foi discutido em Puh e Batista (2016), pois percebe-se que, por vezes, a concepção de cidadania se concretiza nos investimentos em infraestrutura, sem que se dedique a atenção necessária ao fator humano (professores e alunos) ou à criação de espaços públicos adequados à população.

\section{SOBRE O CORPUS E A METODOLOGIA}

Em se tratando do jornal de maior circulação no país e cuja administração está a cargo do Estado angolano, as formações imaginárias acerca dos professores e educação nele presentes contribuem para a formação e estabelecimento de discursos sobre o ideal docente. Nos textos, jornal e Estado alternam-se e confundem-se enquanto enunciadores, portanto, mesmo que não materializados textualmente, há aspectos que indicam as pretensões e aspirações do governo em relação aos futuros professores 
contratados, quer no nível denotativo "superficial" quer no conotativo "profundo" de um texto, na relação desses níveis e no diálogo com outros textos ou documentos.

Há que se considerar também que, para a realização de um concurso público são necessários vários documentos oficiais para a composição do certame, tais como: edital, retificações, provas, informes, listas, entre outros. Os textos divulgados pelo Jornal de Angola não substituem essas publicações oficiais, mas, em alguns casos, disseminam informações, reforçando imagens neles contidas. A confirmação dessa posição está presente em outros espaços jornalísticos, como no site Angonotícias, onde se cita que "o Jornal de Angola, único diário do país, tem regularmente publicado a existência de novas vagas em diferentes instituições governamentais e não governamentais"(ANGONOTÍCIAS, 2014), indicando que seria o lugar onde esse tipo de informações estariam disponíveis. Segundo Becker e Carlos (2015, p. 138) "O Jornal de Angola é o único impresso diário sobre acontecimentos do mundo e do País e o de maior tiragem nacional, com 25 mil exemplares publicados por dia". Além disso, os autores acrescentam que:

As práticas jornalísticas dos veículos de comunicação sob domínio do governo carecem igualmente de pluralismo e independência perante o poder político. Há um peso institucional significativo nos noticiários das rádios e televisão estatais, assim como nas páginas do Jornal de Angola. As fontes oficiais monopolizam a maior parte dos espaços midiáticos. (BECKER e CARLOS, 2015, p. 140)

Desse modo, a escolha dos textos jornalísticos como principal corpus de análise deve-se, principalmente, a dois fatores: a) possibilidade de reconstrução das etapas do certame pelos textos jornalísticos, desde o anúncio até a divulgação e contestação dos resultados, por meio dos textos do jornal, o que permite observar as imagens construídas sobre os professores em cada um desses momentos; b) própria posição do jornal no "entrelugares", como um veículo do discurso institucional estatal, em que é possível encontrar as mencionadas sobreposições e relações interdiscursivas de diversas ordens que possibilitam abordar essas imagens. 
As buscas ao acervo disponível no site do Jornal de Angola resultaram na localização dos seguintes textos sobre o concurso público docente de 2018 :

Texto 1 - Educação admite novos professores (06/03/2018)

Texto 2 - Educação enquadra novos professores (16/04/2018)

Texto 3 - Educação contrata mais de 20 mil professores (29/05/2018)

Texto 4 - Milhares de candidatos concorrem à docência (26/06/2018)

Texto 5 - Vagas na educação atrai muitos jovens (29/06/2018)

Texto 6 - Educação garante lisura no concurso público (11/07/2018)

Texto 7 - Professores aprovados nos testes podem ser conhecidos amanhã $(11 / 07 / 2018)$

Texto 8 - Educação descarta anular concurso (13/07/2018)

Texto 9 - Candidatos apurados são conhecidos hoje (24/07/2018)

Texto 10 - Educação afixa listas do concurso público (25/07/2018)

Texto 11 - Ministério da Educação recuou na admissão de candidatos com nota inferior a dez valores (16/08/2018)

Texto 12 - Concorrentes da capital aguardam pelos resultados (07/09/2018)

Texto 13 - Candidatos a professores com notas acima da média (13/09/2018)

Texto 14 - Professores voluntários (19/09/2018)

Tomando-os por sua ordem de publicação, é possível observar que eles buscam descrever, sucessivamente, o período de anúncio do concurso e as expectativas sobre a contratação de novos professores; o modo como as provas ocorreram; informações sobre os resultados e percalços durante 0 processo. Tem-se, portanto, uma cronologia que reconstrói, textualmente, o evento concurso e permite, mesmo aos que não acompanharam naquele momento o processo, conhecer as expectativas que se tinham acerca dos professores a serem selecionados.

Durante as análises serão destacados trechos de alguns dos textos elencados com vistas a discutir os modos por meio dos quais as imagens sobre o professor são construídas. A opção pela análise de excertos, e não de textos na íntegra, baseia-se na concepção de que cada uma das notas ou notícias faz 
parte de um todo, uma sequência de textos que buscou retratar e comentar o evento concurso. Os aspectos analisados terão como base, principalmente as imagens sobre: a) formação do professor; b) conhecimentos necessários para atuação; e c) aspectos morais. Tais dimensões refletem uma tentativa de categorização que toma por base as abordagens mais recorrentes na cobertura efetuada pelo Jornal de Angola.

\section{ASPECTOS TEÓRICOS}

A principal preocupação deste texto consiste em compreender como se constrói a imagem do futuro professor nos textos jornalísticos e como eles complementam os discursos oficiais, isto é, busca-se entender o perfil profissional que é possível depreender entre os ditos e não ditos do discurso. Para tanto, foram consultados dois autores que versam sobre o tema, discutindo as práticas discursivas que se localizam entre o explicitado e não explicitado, porém subentendido e até no silenciado. Nesse sentido, o exercício de análise concretiza-se na abordagem do discurso como prática social, o que significa que se objetiva entender os efeitos de sentido criados entre interlocutores.

Tomam-se como base as concepções de Pêcheux (1997), seguindo o movimento no qual se interligam o intradiscurso, definindo o discurso como "estrutura", e o interdiscurso, focado no já-dito em outro lugar. De acordo com o autor, o discurso pode ser definido como "[...] pronunciado a partir de condições de produção dadas [...]" (1997, p. 77), sendo que esse também pode ser entendido como prática política, transformado em um lugar de debate onde se confrontam os sentidos. Temporalmente, é possível reconhecer os outros discursos que o precedem, ao mesmo tempo em que se observa como ele aponta para outros. Portanto, o discurso não provém de uma fonte única, mas de várias, as quais não é possível apreender na sua totalidade. Assim sendo, não há sujeitos, nem discurso e nem sentidos prontos e acabados, passando por constantes reconstruções simbólica e historicamente. 
Daí parte-se para a exploração dos implícitos, sem a pretensão da busca do sentido último, verdadeiro ou do sentido oculto, pois existe um imaginário linguístico por meio do qual é possível entender "que o não dito precede e domina o dizer". (PÊCHEUX, 1988, p. 291). Voltando para o não dito, destaca-se que nele existem diversas facetas da linguagem passíveis de serem exploradas, desde o léxico até a semântica e a pragmática. O não dito perpassa e ultrapassa tudo que foi dito, e, segundo Orlandi (2005), ajuda a subsidiar o dito, complementando-o. Desse modo, o não-dizível constitui o espaço do múltiplo, a condição do "vir-a-ser" do discurso, segundo a pesquisadora, que também trabalha com o conceito de silêncio, o qual considera ter um significado próprio e não só complementar, porque permite a fundação do discurso e também é fundado por ele (ORLANDI, 1997).

A autora menciona também diversos tipos de silêncios negativos, resumidos como casos em que contar uma história não é responsabilidade do enunciador; ou que o enunciado é considerado como inexistente; ou que não é enunciável ou que não é direito do destinatário. Como há muitos momentos em que o discurso jornalístico angolano parece procurar preencher e explicitar os silêncios (não) propositais do concurso e suas retificações, optou-se por não trabalhar somente com os não-ditos, acrescentando a eles os silêncios, fundantes da narrativa que foi sendo constituída pelo discurso jornalístico governamental de Angola. Combatem-se silêncios anteriores, "esclarecendo" fatos postos no concurso e suas etapas, ao mesmo tempo que se silencia o que não se consideram adequado através dos ditos e não-ditos.

Ancora-se, portanto, nesse mundo de imagens e imaginários para entender como eles contribuem para definir o perfil dos professores angolanos almejados pelas instâncias oficiais. Assim, mais um construto conceitual que Pêcheux (1997) oferece é a formação discursiva, definida como o lugar de construção dos sentidos, a partir de uma posição e conjuntura de eventos, determinando o que "pode" e "deve" ser dito. Nessa perspectiva, os sentidos são condicionados pelo fato de os discursos se inscrevem na língua e na história, enquanto a mencionada incompletude do discurso conduz o sujeito a se abrir para a exterioridade - naquilo que foi proferido anteriormente em outro 
espaço/tempo. E é nessas entrelinhas daquilo que se espera, exige, propõe e proíbe que se procura encontrar uma formação discursiva que constrói um perfil profissional dos futuros docentes no país.

\section{DITOS E NÃO DITOS SOBRE O PERFIL DOCENTE}

O alto número de docentes que se pretendia contratar por ocasião do concurso associado à escassez de formação específica, seja em cursos de magistérios ou de licenciatura em nível superior, conduziu ao aceite de inscrições provenientes de pessoas com diferentes níveis de formação, como indica o Despacho Conjunto 95/018 na parte destinada à descrição do perfil pretendido:

IV - Perfil dos professores a contratar

a) Requisitos:

1. Nacionalidade Angolana.

2. Idade compreendida entre 18 e 35 anos.

3. Habilitações literárias (Técnico Médio, Bacharelado e Licenciatura obtidas nas Escolas de Formação de Professores).

4. Agregação Pedagógica.

5. Qualificações específicas na disciplina que se candidata para áreas técnicas.

b) No preenchimento das vagas existentes têm preferência:

1. Ensino Primário: Os candidatos habilitados com o Curso de Formação de Professores, efectuado nas Escolas de Magistério e/ou no Instituto/Escola Superior Pedagógica.

2. Ensino Secundário Geral e Pedagógico: Os candidatos habilitados com o Curso de Formação de Professores, efectuado nas Escolas de Magistério e/ou no Instituto/Escola Superior Pedagógica.

3. Ensino Secundário Técnico Profissional: Os candidatos possuidores de qualificações específicas para a disciplina técnica que se candidatam. (Despacho Conjunto n.ำ95/018)

Com relação à formação necessária, destaca-se a menção ao fato de que teriam "preferência" os candidatos habilitados em cursos de formação de professores e com qualificação específica, no caso do ensino secundário técnico profissional. A preferência, entretanto, não exclui a possibilidade de ingresso com outras formações conforme especificações no item "requisitos". 
Os trechos a seguir, advindos do Jornal de Angola, evidenciam o modo como foi abordado esse aspecto:

Excerto 1: "Ao assegurar que os candidatos formados nas escolas de formação de professores a nível médio e superior têm prioridades, Laudemira Sousa [directora nacional de recursos humanos] acrescentou que os técnicos formados nas outras áreas técnicas também vão ser contratados no quadro das necessidades do sector." (texto 3)

Excerto 2: "O presidente do SINPROF [sindicato nacional de professores], Guilherme Silva, chamou a atenção as autoridades governamentais que 'o sector da Educação não é sarjeta, onde quem não se deu bem na outra área encontra uma porta aberta. $A$ educação é para as pessoas formadas nas escolas de formação de professores'. Guilherme Silva avançou que o SINPROF, nos concursos públicos anteriores, fez sempre denúncias, por escrito, relatando a falta de transparência no enquadramento de novos professores, mas nunca foram tidos." (texto 3 )

Nos excertos destacados, provenientes de um mesmo texto, são inseridos, enquanto fontes, enunciadores que representam a esfera governamental e a sindical, configurando os espaços a partir dos quais é possível proferir discursos - lugares do "a ser dito". De um lado, insere-se a voz oficial em discurso indireto como garantia de que a prioridade no concurso será das pessoas com formação específica, entretanto não se exclui a possibilidade de atuação de pessoas formadas em outras áreas. Estabelece-se uma relação condicional, em que a determinação da contratação ou não se dará em função das necessidades da área, as quais, de antemão, já se sabe que são muitas. De outro lado, o enunciado proveniente do representante do sindicato, de maneira metafórica, evidencia a atuação na educação como uma alternativa secundária a pessoas de outras áreas. Nesse sentido, a docência seria uma espécie de salvaguarda para profissionais que não conseguem inserção no mercado de trabalho, esse sendo um dos não-ditos implícitos, pois abre-se na prática espaço para seu ingresso.

Veremos adiante que isso se aplica aos jovens como mais um grupo para o qual se pressupõe que atuar na educação do país seja uma opção de trabalho, permitindo ao governo manejar com as necessidades propostas nas Reformas Educativa e Administrativa, mas também com o desemprego de modo geral. 
O uso de "sarjeta" não se refere somente a lugar de acolhida a quem não tem outras opções, mas também dá a entender que seria uma condição de marginalização e humilhação. Seu emprego, embora tenha sido como negação, chama a atenção para uma determinada imagem dos professores e da educação que o enunciador representante sindical acredita ser a de profissionais de outras áreas. Aqui são pertinentes as considerações sobre as "antecipações das representações do receptor" (PÊCHEUX, 1997, p. 84), segundo as quais seria possível inferir formações imaginárias cuja pergunta poderia corresponder a "que imagem o jornal faz da imagem que os leitores têm sobre a educação e os professores?". Cabe ressaltar que, apesar de se tratar de um trecho em discurso relatado, a opção por inseri-lo e o modo como essa inserção se dá é do enunciador jornal, que o apresenta como "discurso principal", enquanto o do sindicado é posto como "secundário" para auxiliar na composição do discurso institucional acerca do tema.

A seguir são dispostos excertos de textos publicados após a realização das provas e antes da divulgação dos resultados, ambos se compõem de discurso relatado cujos enunciadores são representantes do governo:

Excerto 3: "O sector da Educação tem sido a salvação de muitos jovens que procuram o primeiro emprego. No presente concurso público, privilegiamos todos os cidadãos angolanos formados na área da Educação", disse a ministra, acrescentando que o Executivo está a criar novas formas para gerar postos de trabalho, não só no sector que dirige, mas também noutras áreas sociais". (texto 7)

Excerto 4: "É necessário que a juventude no Cuando Cubango tenha calma e se prepare melhor para o próximo concurso público, tendo em conta que quem não foi admitido desta vez é porque teve nota negativa ou idade superior a 35 anos [enunciado do director provincial do sector de Educação]"' (texto 13)

No excerto 3, de modo semelhante ao que ocorre no excerto 1, é enfatizada a voz oficial segundo a qual os profissionais com formação específica serão privilegiados, embora não se mencione em nenhum dos quatorze textos publicados pelo jornal de que forma isso ocorreria - aqui se silenciam as condições. Por se tratar de enunciado atribuído à dirigente máxima nos assuntos educacionais do país, o discurso direto no excerto 3 confere ao texto o tom de oficialidade; nesse sentido, cabe observar que a 
afirmação de que a área educacional tem sido "a salvação de muitos jovens que procuram o primeiro emprego" contrasta com as declarações, também oficiais, acerca da formação necessária ao professor. Aqui também é necessário salientar o uso do termo "salvação", que se pode inserir em um discurso de risco social (de desemprego, de marginalidade, de falta de oportunidade) e também em um discurso oficial com características religiosas (possível vítima e salvador).

Já no excerto 4, em texto que discutiu a quantidades de vagas disponíveis e preenchidas na província de Cuando Cubango, há a nomeação dos possíveis futuros professores como "juventude", numa alusão ao fato de o concurso estabelecer como idade limite para os inscritos 35 anos. Pessoas além dessa idade não poderiam se inscrever e, caso o tivessem feito e sido aprovadas, não conseguiriam assumir as vagas, tal restrição está prevista no Decreto $n . \stackrel{25 / 91}{\text {, de }} 29$ de junho de 1991. Assim, o exercício docente tem sido associado a pessoas mais jovens, possivelmente numa tentativa de mantê-las por mais tempo em atuação no magistério, além de proporcionar a mencionada oportunidade de começar uma carreira.

Porém, para esse limite também existiram algumas exceções, como para os veteranos de guerras com formação ou cidadãos que se formaram e moram no exterior, enunciados "ditos" pela ANGOP (Agência Angola Press), agência de notícias governamentais que disseminou essa notícia pelo Jornal de Angola em 2008, com validade de cinco anos (JORNAL DE ANGOLA, 2019). Aqui há um não-dito pouco evidente para quem não vivenciou a realidade do país e não conhece as condicionantes históricas que fizeram com que muitos dos quadros mais educados emigrassem ou procurassem formação fora do país, além da necessidade de reinserção social dos combatentes de guerra. Ou seja, foram se fazendo adendos para essa legislação com vistas a atender as demandas de determinados setores, abrindo possibilidades de percepções diferenciadas para as quais se considerou que eram necessárias adaptações, sendo uma tendência em outros casos a serem explicitados.

Para além do aspecto da juventude como uma característica associada aos futuros professores e à própria atuação docente, são frequentes nos textos 
menções aos conhecimentos necessários ao professor. Embora não tenham sido inseridas informações acerca dos conteúdos fundamentais para o exercício da profissão, os textos indicam uma preocupação com o número mínimo de acertos para aprovação no concurso. Aqui cabe destacar que, apesar de se tratar de um concurso nacional, a responsabilidade sobre 0 conteúdo e a própria estrutura das provas estavam a cargo dos governos provinciais, não havendo, portanto, um padrão único a ser seguido.

Pesquisas sobre concursos públicos para professores realizados no Brasil indicam que há grande variação com relação às estruturas das provas e aos tipos de questões. Em Batista (2016), por exemplo, em estudo que discute as imagens do professor de língua portuguesa em concursos públicos de municípios da Grande São Paulo, fez-se a seguinte observação: "Com relação às provas, elas variam em número de questões, áreas do conhecimento avaliadas e formas de avaliação (questões de múltipla escolha, dissertação ou questões dissertativas)" (BATISTA, 2016, p. 27).

Ainda nesse estudo, são apresentadas análises que permitem discutir se, nas provas de concursos para professores, o que se pretende é mensurar o conhecimento do candidato em uma dada área do conhecimento ou ratificar determinadas correntes teóricas por meio da seleção. De todo modo, há que se considerar que afirmar que um candidato obteve um determinado percentual de acertos em um concurso público não corresponde a assumir que esse percentual corresponda ao seu nível de conhecimento em uma área do conhecimento, não obstante ser essa a compreensão mais frequente. Aqui se silenciam de fato as condições necessárias para que o futuro docente possa atuar, pertencente ao que Orlandi (2007) chama de silêncio negativo - aquele que não é responsabilidade do destinatário do discurso, embora seja testado para tal.

No caso do concurso de Angola, a ausência de informações acerca do cálculo para aprovação ou não dos candidatos nos documentos orientadores abriu margem para questionamentos sobre a linha de corte da seleção. No Despacho Conjunto 95/018, foram dispostas somente as seguintes informações sobre a correção das provas: 
6. Correção dos testes

A avaliação, correção das provas, publicação e afixação das listas contendo os resultados é feita obedecendo, escrupulosamente, os seguintes princípios:
a) objectividade;
b) rigor;
c) transparência;
d) isenção;
e) imparcialidade;
f) direito à reclamação/recurso do candidato.

As notas atribuídas poderiam estar em uma escala entre 0 e 20 valores; após as correções, para que fosse possível preencher o número de vagas, segundo o Jornal de Angola, houve anúncios oficiais de que mesmo aqueles com nota inferior a 10 valores poderiam ser convocados em razão da necessidade de inserção de uma grande quantidade de profissionais nas escolas, entretanto, logo em seguida, houve um recuo, como se vê no trecho a seguir:

Excerto 5: "O Ministério da Educação recuou na admissão de candidatos que tiveram uma nota inferior a dez valores no concurso público de ingresso de professores, ao contrário do que havia publicado, no mês passado, dias depois da realização das provas. Em comunicado, o Ministério da Educação diz que os candidatos a admitir são aqueles cujas notas estão no intervalo entre 20 e 10 valores, na ordem decrescente e vai ser em função do número de vagas disponíveis." (texto 11)

Percebe-se um movimento de explicitação de um não-dito presente no discurso público que teve de ser silenciado pela emissão de um comunicado que anulou outras possibilidades de interpretação. Este comunicado a que o jornal se refere corresponde à nota de imprensa do Gabinete de Comunicação Institucional e Imprensa, emitida em 13 de agosto de 2018, nela há as seguintes informações sobre os valores necessários à aprovação dos candidatos:

5. É nos termos destas qualificações [recomendadas para os professores] que se determinou que a nota mínima para a admissão dos candidatos é de 10 valores. Assim sendo, os candidatos a admitir serão aqueles cujas notas estão no 
intervalo entre 20-10 valores na ordem decrescente na razão do número de vagas disponíveis.

Outra voz mobilizada pelo jornal para discutir a nota mínima dos aprovados foi a de um sociólogo e professor que criticou a decisão inicial de admitir os candidatos que obtiveram menos de dez valores. Traz-se o seu comentário da seguinte forma:

Excerto 6: "O sociólogo e professor universitário Paulo de Carvalho criticou, há dias, nas redes sociais, o Ministério da Educação por ter optado pela admissão de candidatos a professores que reprovaram no concurso. Paulo de Carvalho comentou o facto de o concurso público não ter estabelecido inicialmente a nota mínima para a admissão, dando o exemplo do que acontece numa sala de aula, quando se aplica uma prova, onde há notas positivas e negativas. O sociólogo acentuou, mencionando as pautas que circulam pelas redes sociais, que foram admitidos candidatos que obtiveram na prova de selecção notas de nove e até de dois valores em 20 possíveis." (texto 11)

A inserção de um enunciador ligado ao saber acadêmico, para além de marcar a posição de uma instância da sociedade frente à questão, mostra-se como um recurso argumentativo de autoridade. Na medida em que o jornal se vale de uma voz previamente reconhecida, crítica à admissão de professores com baixo desempenho nos exames, reforça a imagem do professor como aquele que deve dominar os conhecimentos teóricos de sua área. Assim, acrescenta-se um novo dito ao que já foi dito sobre o assunto, criando um espaço de tensão entre essas diferentes instâncias discursivas nas quais 0 enunciador e, consequentemente, o jornal, tecem críticas da atitude governamental e seus silêncios no que se refere a esse tema. Ou seja, criticam-se as decisões e ações governamentais que não pertenciam ao mundo do dito, colocado nos despachos e no edital do concurso.

Outro aspecto, ao qual se dedica atenção no discurso apreendido no Jornal de Angola, é o da moralidade, especificando-se o que não seria desejável num futuro professor.

Excerto 7: "O concurso público para admissão de professores, em curso nos 14 municípios da província de Malanje, vai decorrer dentro das normas estabelecidas, consubstanciadas na transparência e lisura na correcção das provas, assegurou ontem o director do Gabinete Provincial da Educação, Gabriel Boaventura. [...] O 
director da Educação apelou aos candidatos para não se deixarem enganar por pessoas que prometem facilitar nas provas em troca da "famosa gasosa", pois quem incorrer nesta prática 'vai responder à Justiça'." (texto 6)

Há enunciados de alguns dirigentes, como o do Diretor da Educação da província de Malanje no excerto 7 , em que se menciona o imperativo de se evitar a recorrer ao uso da "famosa gasosa". Essa metáfora possibilita o entendimento do funcionamento de alguns setores ou práticas da sociedade em que acontecem práticas corruptas, recomendando-se, no caso dos professores, a não se "deixarem enganar por pessoas que prometem facilitar nas provas", uma vez que isso resultaria na necessidade de o candidato "responder à Justiça". Percebe-se, portanto, o acionamento do discurso jurídico como represália na tentativa de construir um discurso acerca da moralidade da atuação dos futuros docentes, presente como aspecto não-dito do discurso governamental. Não se dizem quais são as características morais ou éticas dos candidatos, mas comenta-se aquilo que não seria desejável, referindo-se a práticas reais que implicitamente já são conhecidas na sociedade. Percebe-se a mesma preocupação com a moralidade em comunicado de imprensa emitido pelo Gabinete de Comunicação Institucional e Imprensa do Ministério da Educação, publicado em 25 de junho de 2018:

[...] 2. Serão acionadas todas disposições legais para sancionar actos de corrupção que pretendam interferir no concurso público para docência actualmente em curso;

3. O Ministério da Educação solicita e encoraja a denúncia de quaisquer actos ou procedimentos que configurem favores e que ponham em causa a lisura e transparência na execução do processo de ingresso de novos docentes. [...]

Em período posterior do concurso, já durante as etapas de correção, houve comentários sobre as irregularidades da avaliação e apuração das notas inferiores ao mínimo, citando aspectos geográficos ao destacar a região de Luanda e também aspectos dos agentes que trouxeram esse assunto à tona "os candidatos supostamente prejudicados" e "a sociedade acadêmica". Curiosamente, o objeto das reclamações é o próprio concurso público, evitando-se dizer quem era o autor do mesmo, como se vê no excerto seguinte: 
Excerto 8: "O concurso público na Educação, que abriu em Junho deste ano, foi bastante contestado pela sociedade académica, pelo facto de, inicialmente, ter apurado candidatos com notas inferiores a dez valores e ter registado irregularidades em algumas províncias, com destaque para Luanda. Perante a pressão exercida pelos candidatos supostamente prejudicados, o Ministério da Educação recuou na posição e anunciou, em comunicado, no mês passado, que apenas vai seleccionar os concorrentes com nota superior a dez valores." (texto 12)

O fato de os candidatos e os acadêmicos reclamarem dessa prática, fez com que o Governo recuasse e decidisse selecionar somente aqueles com nota maior que dez, saindo com o seu pronunciado do silêncio atribuído a esse ocorrido. Também, definem-se procedimentos presentes nas irregularidades, como a prática de alteração da avaliação baixa, a qual segundo o jornal seria para "apurar um familiar, amigo ou vizinho", indicando o alvo dessas práticas que seria da esfera mais íntima do candidato, como vemos no excerto 9:

Excerto 9: "Segundo o director do Gabinete Provincial da Educação, foram encontrados exames em que os candidatos tiveram 17 ou 15 valores, mas que na verdade tiveram notas negativas, porque as pessoas que corrigiram as provas colocaram o número um em frente de algumas classificações negativas, para fazer apurar um familiar, amigo ou vizinho." (texto 13)

Desse modo, a (i)moralidade do assunto estaria dissipada entre diversos atores envolvidos no concurso, encaminhando a discussão para a esfera societal ou comunitária, onde o professor seria um dos envolvidos nas práticas ilícitas.

\section{CONSIDERAÇÕES FINAIS}

Posto que a realização de um concurso de grande impacto na sociedade e de abrangência nacional colocou em discussão em Angola, mesmo que indiretamente, o que se pretendia dos futuros professores a serem contratados, o Jornal de Angola, como colaborador da atuação governamental no plano de discurso público, o tratou como um grande acontecimento, acompanhando cada passo, desde o seu anúncio até a divulgação dos resultados. Nesse jogo de vozes, entre os documentos oficiais (leis, despachos e comunicados de 
imprensa) e textos jornalísticos, houve uma relação de complementaridade, em que o que não havia sido dito por aqueles era indicado por estes, formando-se uma narrativa de muitos movimentos do dito, não-dito, silenciado e contradito, expandindo as considerações de Pêcheux (1997) acerca do interdiscurso.

Os não ditos no nível da oficialidade encontraram espaço no âmbito jornalístico, como ocorreu com a nota de corte dos candidatos, tendo sido estipulada em dez valores somente após repercussão negativa materializada pelo jornal. Assim, mesmo os aspectos abordados em tom de crítica ao governo apresentavam espaço para as respectivas correções. No episódio relativo às notas que foram alteradas, discutido no excerto 9, se, por um lado, coloca-se em destaque a fragilidade dos mecanismos de correção das provas, contrariando as orientações constantes no Despacho Conjunto 95/018, por outro, ratifica-se o esforço do governo em coibir essas práticas.

A movimentação entre diferentes tipos de discursos - científico, político e governamental - também resulta na alteração de ditos e não-ditos, às vezes, explicitando o que foi silenciado previamente e em outras silenciando ao dizer aquilo que deveria constar como o fato oficial. Houve casos em que se manifestaram os contraditos, elementos de discurso científico e jornalístico utilizados para criticar ou se contrapor ao discurso político. Percebe-se assim que o discurso público, criado a partir do entrelaçamento destes diferentes modos de dizer, possibilita o evidenciamento de um interdiscurso complexo e lança várias imagens sobre o perfil de futuro professor da rede pública angolana. Esse professor precisaria ter as competências previstas não somente no despacho e nas leis, mas também em notas emitidas pelo governo e posteriormente pelos jornais, incidindo sobre diferentes imagens.

Inicialmente, há a imagem da formação do professor, discutindo-se o ingresso de profissionais que não tiveram formação estritamente pedagógica, bem como a idade ideal (entre 18 e 35), que permitiria este ingresso aos jovens. Posteriormente foram discutidos os conhecimentos necessários para atuação, mais especificamente a avaliação mínima para o ingresso na carreira docente e os registrados desvios dos critérios previstos. E por fim, os aspectos morais relacionados com a atuação do docente nas provas e a aceitação de 
comportamentos inaceitáveis, fortemente combatidos pelo discurso jurídico que o governo incluía nos seus enunciados.

\section{REFERÊNCIAS}

ANGOLA. Assembleia Nacional. Lei n. 13, de 31 de dezembro de 2001. Nova Lei de Bases do Sistema de Educação. Diário da República, I Série, 2001.

Balanço da Implementação da 2ª Reforma Educativa em Angola. Luanda: Ministério da Educação, 2011.

Ministérios da Administração do Território e Reforma do Estado e da Educação. Despacho Conjunto n. 95/018, de 12 de abril de 2018. Diário da República, I Série n. 48, 2018.

Ministério da Cultura. Nota de imprensa do Gabinete de Comunicação Institucional do Ministério da Cultura, 21 de julho de 2018.

2018.

. Ministério da Educação. Despacho n. 232/018, de 18 de maio de

- Ministério da Educação. Comunicado do Gabinete de Comunicação Institucional e Imprensa do Ministério da Educação, 25 de junho de 2018.

Decreto n.․ 25/91, de 29 de junho de 1991 .

ANTÓNIO, P. R. A reforma administrativa em Angola: retrospectiva e perspectivas. In: Congreso Internacional del CLAD sobre la Reforma del Estado y de la Administración Pública, IX. Madrid, España, 2, 5 nov. 2004.

BATISTA, Adriana Santos. Imagens do professor de língua portuguesa em concursos públicos. São Paulo: Paulistana, 2016.

BECKER, Beatriz; CARLOS, Albino. Mídia e Jornalismo em Angola: uma radiografia. Revista Brasileira de História da Mídia (RBHM) - v.4, n.2, jul./2015 - dez./2015.

Excepção ao limite de idade é uma Lei antiga. Jornal de Angola. Luanda, 5 de setembro de 2013. Disponível em:

http://jornaldeangola.sapo.ao/politica/excepcao_ao_limite_de_idade_e_uma_lei _antiga. Acesso em 13 de abril de 2019.

Jovens denunciam barreiras de acesso ao primeiro emprego. Angonotícias. Luanda, 24 de fevereiro de 2014. Disponível em: 
http://www.angonoticias.com/Artigos/item/41662/jovens-denunciam-barreirasde-acesso-ao-primeiro-emprego. Acesso em 13 de março de 2019

ORLANDI, Eni Puccinelli. Análise do discurso: princípios e procedimentos. 5. ed. Campinas, SP: Pontes, 2005.

PÊCHEUX, Michel. Análise automática do discurso (AAD-69). In: GADET, Francoise; HAK, Tony. Por uma análise automática do discurso: uma introdução à obra de M. Pêcheux. Campinas: Ed. da Unicamp, 1997. p. 61-105.

Semântica e discurso: uma crítica à afirmação do óbvio. Campinas: Ed. da Unicamp, 1988.

Professores admitidos em 2018 inseridos nas folhas de salários. Agência Angola Press. Luanda, 11 de outubro de 2018. Disponível em https://www.angop.ao/angola/pt_pt/noticias/educacao/2018/9/41/Professoresadmitidos-2018-inseridos-nas-folhas-salarios,9be6b5fc-f000-4416-93929c74e613cfdf.html. Acesso em 08 de abril de 2019.

PUH, Milan; BATISTA, Adriana Santos. Escolas como fábricas: análise de representações sobre educação. RDIVE - Revista Discurso e Imagem Visual em Educação, João Pessoa, v.1, n. 2, p. 25-41, 2016.

SILVA, Rita Mafalda Cavaco Simões Bourguignon. A importância da educação na manutenção da paz e reconstrução de Angola. Dissertação de mestrado. Universidade Autônoma de Lisboa, 2013.

UNICEF. O acesso a uma educação de qualidade é um direito. Disponível em https://www.unicef.org/angola/educacao, 2018. Acesso em 04 de abril de 2019.

VALADARES, Josiel Lopes et al. Brasil e Angola: convergências e divergências epistemológicas sobre os modelos de administração pública. Revista de Ciências da Administração, Florianópolis, p. 131-142, ago. 2013.

Recebido em: 27/04/2019

Aprovado em: 04/07/2019 